\begin{tabular}{|c|c|c|}
\hline \multicolumn{3}{|c|}{$\begin{array}{l}\text { OPEN O ACCESS Freely available online } \\
\text { http://www.banglajol.info/index.php/BJID/index }\end{array}$} \\
\hline Perspective & & \\
\hline $\begin{array}{l}\text { Bangladesh Jc } \\
\text { October 2020, Volume } 7 \text {, }\end{array}$ & $\begin{array}{l}\text { al of Infectious Diseases } \\
\text { r Suppl_2, Page S63-S66 }\end{array}$ & \\
\hline $\begin{array}{l}\text { ISSN (Online) 2411-670X } \\
\text { ISSN (Print) 2411-4820 }\end{array}$ & DOI: https://doi.org/10.3329/bjid.v7i00.50166 & \\
\hline
\end{tabular}

\title{
Is Bangladesh Moving toward Herd Immunity? Current COVID-19 Perspective
}

\author{
Md. Jamal Hossain \\ Department of Pharmaceutical Chemistry, Faculty of Pharmacy, University of Dhaka, Dhaka-1000, Bangladesh
}

[Received: 17 August 2020; Accepted: 28 September 2020]

\begin{abstract}
Globally, a spectrum of infectious disease outbreaks like SARS in 2013, Ebola in 2014, MERS in 2015, and currently COVID-19, have affected us in the early phase of this century and coerced the people across the world to search the adamant control measures to avert the pandemic by any means. Unfortunately, high economic costs and resource-limitations, especially in low-and middle-income countries, restrict the adoption of the epidemic control measures in most cases. Since late December of 2019, the SARS-CoV-2 virus has been creating a breakneck public health concern worldwide. Currently, there is no effective drug to tackle the COVID-19 infection or vaccine yet to be approved. An old-age concept, herd immunity might be a prospective option in this uncertain situation to fight the COVID-19 pandemic. A minimum fraction of people need to be immunized through vaccination or previous infection to attain the herd immunity base that may build an obstacle to free the community from the disease. The insusceptible or indirectly immunized people can act as an invisible shield to impede the epidemic's dispersion anymore. [Bangladesh Journal of Infectious Diseases, October 2020;7(suppl_2):S63-S66]

Keywords: SARS-CoV-2, Infectious disease, COVID-19 pandemic, Vaccination, Herd immunity, Bangladesh

Correspondence: Md. Jamal Hossain, Department of Pharmaceutical Chemistry, Faculty of Pharmacy, University of Dhaka, Dhaka-1000, Bangladesh; Cell no.: +88 01517814 866; Fax: +88-02-9667222; Email: jamal.du.p48@gmail.com; ORCID iD: https://orcid.org/0000-0001-9706-207X

Conflict of interest: The author declared no conflicts of interest.

Funding agency: The author did not receive any type of funding regarding this work.

Contribution to authors: Author has done all write up.

How to cite this article: Hossain MJ. Is Bangladesh Moving toward Herd Immunity? Current COVID-19 Perspective. Bangladesh J Infect Dis 2020;7(suppl_2):S63-S66

Copyright: (02020. Hossain. Published by Bangladesh Journal of Infectious Diseases. This article is published under the Creative Commons CC BY-NC License (https://creativecommons.org/licenses/by-nc/4.0/). This license permits use, distribution and reproduction in any medium, provided the original work is properly cited, and is not used for commercial purposes.
\end{abstract}

\section{Introduction}

The entire world has been suffering from a highly contagious and transmissible coronavirus disease 2019 (COVID-19) since late December of the last year. The World Health Organization (WHO) assessed the severity of the disease provoked by an etiological agent denominated severe acute respiratory syndrome coronavirus 2 (SARS-CoV-2) and declared a pandemic on March 11, 2020 ${ }^{1}$. As of
September 30, 2020, the whole world enumerated more than 33.8 million gross infections, with around 1.01 million deaths ${ }^{2}$. The COVID-19 epidemic in Bangladesh is an organ of the current global pandemic. The first three COVID-19 positive cases were ascertained in Bangladesh on March 8, 20203. The rate of the SARS-CoV-2 infection was negligible during March but showed steeper in early May of the year. Meanwhile, the infectious disease has already pervaded in every corner of the country and augments the death toll 
day by day. Up to September 30, 2020, Bangladesh computed its cumulative cases of infections of 363,479 with 5,251 deaths, and till the same date, 275,487 patients got COVID-19 recovery reports ${ }^{2}$. Unfortunately still now, there is no effective and approved drug or vaccine to combat the SARSCoV-2 virus. Therefore, we must rely on some symptomatic treatments, supportive care, and some uncertain repurposed drugs to tackle the infection.

From the embryonic stage of this pandemic, the term 'herd immunity', which is hardly conversant to an expert, has created a vociferation globally and nationally. Herd immunity or herd effect or indirect protection or community immunity is not a neoteric concept. Sensibly, we may suggest three approaches to fight a newly emerging viral transmission. Firstly and most importantly, to impede the transmission of the virus by adopting some adamant control measures like maintaining social distancing, quarantine, effective lockdown, using masks, sanitization, etc. Developing an effective vaccine against the virus and attaining community immunity or herd immunity might be the second and third options, respectively, to save the mass people from a nascent deadly virus. In most cases, Bangladesh could not be successful in fulfilling the first strategy, and an effective and approved vaccine is yet to be developed worldwide. Therefore, the third strategy is only open to adjourn this lethal infection $^{4,5}$.

\section{Herd immunity: A plausible strategy in Bangladesh?}

Herd immunity theorizes a pathogenic virus's annexation to a human or animal population model to develop immunity or indirect protection against the causative agent for a nosogenic infectious disease. The abstract conviction is that herd immunity may be achievable when a significant portion of the population develops immunity through vaccination or from antecedent contagion. The inference connotes that herd immunity may act as buffers between the susceptible people who are not immunized to infection. Once the chain of contagious transmission is hindered due to a lack of finding a viable host by the virus, and the disease will eventually be eradicated ${ }^{5}$. As we lack an effective vaccine, we have no way rather than to adopt natural herd immunity.

To comprehend the threshold percentage of the population required to be immunized for reaching heard immunity, it is mandatory to estimate precisely the average basic reproduction or reproductive number $\left(\mathrm{R}_{0}\right)$ value. The $\mathrm{R}_{0}(\mathrm{R}$ naught or $\mathrm{R}$ zero) denotes the average number of infected patients in a population from one infected patient over the infection period where no one is immune. The $\mathrm{R}_{0}$ value varies from location to location due to geographical and environmental variations, culture, contact rate among people, health conditions, outbreak level, etc. It is important to note here that $\mathrm{R}_{0}$ is a useful parameter to forecast the commencing, surge, and phasing out of the outbreak by the public health experts. $R_{0}>1$ indicates the exponential rise of the infection, $\mathrm{R}_{0}<$ 1denotes the shrinking of the epidemic, and $\mathrm{R}_{0}=1$ means the infection rate always remains constant ${ }^{6}$. By utilizing the following formula, epidemiologists enumerate the threshold level (minimum percentage $=\mathrm{P}$ ) requiring immunization for gaining herd immunity ${ }^{7}$.

$$
\mathrm{P}=\left(1-\frac{1}{\mathrm{R}_{0}}\right) \times 100 \%
$$

In most global studies and estimation of WHO, the $\mathrm{R}_{0}$ values were tentatively 1.4 to $3^{8,9}$. Due to inadequate testing, data limitations, and prejudiced reporting may be the barriers to estimate a precise and representative $R_{0}$ value of Bangladesh. However, the calculated $\mathrm{R}_{0}$ value in India is 1.379 (range: 1.29 to 1.45$)^{10}$, which may resemble the approximate $\mathrm{R}_{0}$ value of Bangladesh. Therefore, the threshold percentage may be assumed as 22 to $31 \%$ of the total population required to achieve indirect protection through natural herd immunity in Bangladesh.

According to the Institute of Epidemiology, Disease Control and Research (IEDCR), as of September 30 , Bangladesh got total 363,479 infections, which stand for near $0.22 \%$ of the total population of the country (168 million). Unfortunately, the COVID19 testing rate in Bangladesh is far lower beyond imagination. IEDCR had just tested 11,223 suspected patients in the first five weeks after the first case detection in Bangladesh, which constituted to be one of the worst-ranked countries for COVID-19 tests, approximately 68 tests/million people ${ }^{11}$. Although the testing rate was rising day by day, the rate had declined drastically in August and September of the year. It is another stigma that the government has applied charges for COVID-19 tests, which created barriers, especially for poor people $^{12}$. The Lancet has recently reported that the death rate is four times higher than the authoritatively declared numbers, and the situation has created un-trust in people's minds of Bangladesh $^{12}$. 
Theoretically, it seems nearly inconceivable to touch the bottom line of the herd immunity without an effective vaccine. Nevertheless, it may be plausible, according to the claim of The Economist, a leading UK-based weekly, on June 4, 2020, Dhaka originally faced 36 times higher infections than the official declaration ${ }^{4}$. A recent study conducted by IEDCR in collaboration with International Centre for Diarrhoeal Disease Research, Bangladesh (ICDDR'B), has revealed that 2 million Dhaka city dwellers (roughly 9-10\%) could be COVID-19 positive along with $78 \%$ asymptomatic that is much higher than the government announcement ${ }^{13}$. Another report figured out from the survey study that around 10 million or near $50 \%$ of people of the capital city of Bangladesh developed antibodies against SARSCoV-2 infection ${ }^{14}$. The rate was a whopping $74 \%$ among slum dwellers ${ }^{14}$. The percentage is much higher to reach herd immunity in the slum area. Researchers perceive that this massive number of asymptomatic infected people are going back to workplaces, walking streets or markets, and doing mundane routine tasks as usual.

It is easily understandable that the hotspots for COVID-19 infection are the hospitals, diagnostic centers, airports, markets, super shops, immigration points, stations, etc. During the pandemic time, the immunized volunteers recovered from COVID-19 might be recruited for these susceptible places as per their experiences. The immunized people by developing neutralizing antibodies (Nabs) against the SARS-CoV-2 virus would avert the transmission of the infection and fight in the root points to construct community protection.

It is crucial to bear in mind that herd immunity will be ineffective in viral mutation and recurrence of infection. Batisse et $\mathrm{al}^{15}$ have recently reported a case series study on eleven re-infected COVID-19 patients. This reinfection is alarming and a hindrance to herd immunity. The study recommended for comprehensive research to perceive the mechanism of the SARS-CoV-2 reinfections or reactivations. However, this disputable outcome of COVID-19 reinfection is yet to be substantiated, and some experts envisaged the reactivation of dormant SARS-CoV-2 infection ${ }^{16}$.

Moreover, herd immunity or community immunity is an experimented strategy. All the places are not uniformly prone to infection in developing countries. The $\mathrm{R}_{0}$ values are not equal for the rural and urban areas. In the city area or mega city like Dhaka, a substantial, dense population frequently has to use unhygienic public transports, stations, shopping malls, local markets, etc. which may augment the risk of SARS-CoV-2 viral transmission. This current higher jeopardy in Dhaka is likely to endorse the prior speculation of The Economist. Therefore, localized herd immunity or community immunity may assist in suppressing the spread of SARS-CoV-2 infection ${ }^{17}$.

It is a beacon of hope that some vaccines are under investigation in human trials, phase $2 / 3$, and seemingly the Bangladesh government has heretofore commenced diplomacy with various potential COVID-19 vaccine developed countries to fetch once it is approved through safely and effectively. The achievement of herd immunity will be accelerated through the vaccination without mass people getting sick. Despite facing the solicitous multiple waves of infection in the herd immunity strategy, a significant portion of people is going to be immunized through antibody development yet to be tested vigorously in Bangladesh. Thus, indirectly immunized or antibody-developed people may act as a barrier to propagate the SARS-CoV-2 infection anymore.

\section{Conclusion}

Even though the implementation of herd immunity is challenging and risky, the economic circumstance in a developing country triggers the approach. Likely in Bangladesh, there is no secondary injunction to get rid of the pandemic. Perhaps, no ultimatum catastrophic situation or what subversive outcomes are correlated, Bangladesh moves towards executing an undeclared and experimental herd immunity. However, achieving practical herd immunity or not, we must be concerned for our elderly and not immunized population, boosting up the number of tests vastly, infection control surveillance, and ameliorating current health care status.

\section{References}

1. WHO. Coronavirus disease 2019 (COVID-19) situation report 51. Accessed March 11, 2020. Available from: https://www.who.int/docs/default-

source/coronaviruse/situation-reports/20200311-sitrep-51covid-19.pdf?sfvrsn=1ba62e57_10.

2. Worldometer. Accessed September 30, 2020. Available from: https://www.worldometers.info/coronavirus/.

3. Paul R. Bangladesh confirms its first three cases of coronavirus. Reuters. 2020. Available from: reuters.com/article/us-health-coronavirus-bangladeshidUSKBN20VOFS

4. Akhand AA. Hard consequences and hope of herd immunity. New age. Accessed July 17, 2020. Available from: https://www.newagebd.net/article/108591/hard-consequences- 
and-hope-of-herd-immunity.

5. Popy RF. Herd Immunity of Covid19- Goal or Outcomes? Bangladesh J Infect Dis 2020; 7: S61-S62.

6. Mahase E. Covid-19: What is the R number? BMJ 2020; 369: $\mathrm{m} 1891$

7. Fine P, Eames K, Hey DL. "Herd Immunity": A rough guide. Clin Infect Dis 2011; 52: 911-916.

8. Tang B, Bragazzi NL, Li Q, Tang S, Xiao Y, Wu J. An updated estimation of the risk of transmission of the novel coronavirus (2019-nCoV). Infect Dis Model 2020; 5: 248-255.

9. Liu Y, Gayle AA, Wilder-Smith A, Rocklöv J. The reproductive number of COVID-19 is higher compared to SARS coronavirus. J Travel Med 2020; 27: taaa021

10. Marimuthu S, Joy M, Malavika B, Nadaraj A, Asirvatham ES, Jeyaseelan L. Modelling of reproduction number for COVID-19 in India and high incidence states. Clin Epidemiol Glob Health 2020

11. Anwar S, Nasrullah M, Hosen MJ. COVID-19 and Bangladesh: challenges and how to address them. Front Public Health 2020; 8

12. Cousins S. Bangladesh's COVID-19 testing criticized. Lancet 2020; 369
13. Daily star. Nearly 20 lakh Dhaka residents could be Covid19 positive, 78\% asymptomatic: study. Accessed August 11, 2020. Available

from: https://www.thedailystar.net/coronavirus-deadly-newthreat/news/nearly-20-lakh-dhaka-residents-could-be-covid-19positive-78-asymptomatic-study-1942953.

14. Tajmim T. Dhaka slum dwellers develop herd immunity. The Business Standard. Accessed October 12, 2020. Available from: https://tbsnews.net/coronavirus-chronicle/covid-19bangladesh/45-dhaka-population-develops-covid-19-

antibodies-144205.

15. Batisse D, Benech N, Botelho-Nerves E, Bouiller K, Collarino R, Conard A, et al. Clinical recurrences of COVID19 symptoms after recovery: viral relapse, reinfection or inflammatory rebound? J Infect 2020

16. Gallagher J. Coronavirus immunity: Can you catch it twice? BBC news. Accessed August 24, 2020. Available from: https://www.bbc.com/news/health-52446965.

17. Syal K. COVID-19: Herd immunity and convalescent plasma transfer therapy. J Med Virol 2020. 